\title{
Characteristics of frequent users of emergency departments in Alberta and Ontario, Canada: an administrative data study
}

\author{
Anqi Chen ${ }^{1} \cdot$ Maria Ospina ${ }^{2,3} \cdot$ Andrew McRae $^{4,5} \cdot$ Patrick McLane $^{6,7} \cdot$ X. Joan $\mathrm{Hu}^{8} \cdot$ Scott Fielding ${ }^{6}$. \\ Rhonda J. Rosychuk ${ }^{1,8,9}$ [
}

Received: 5 June 2020 / Accepted: 6 October 2020 / Published online: 4 January 2021

○ Canadian Association of Emergency Physicians (CAEP)/ Association Canadienne de Médecine d'Urgence (ACMU) 2021

\begin{abstract}
Objective Frequent users to emergency departments (EDs) are a diverse group of patients accounting for a disproportionate number of ED presentations. This study examined sociodemographic and ED visit characteristics of adult high-system users in two Canadian provinces.

Methods Cohorts of high-system users were created for Alberta and Ontario including patients with the top 10\% of presentations in the National Ambulatory Care Reporting System (April 2015-March 2016). Controls were random samples of non-high-system user patients. Sociodemographic and ED visits data were used to predict high-system user group membership in a multivariable logistic regression model.

Results There were 579,674 high-system users and 2,115,960 controls. High-system users were more likely to be female [odds ratio $(\mathrm{OR})=1.1,95 \%$ confidence interval $(\mathrm{CI}) 1.1,1.1$ ], older (OR 1.02 per 5 years, $95 \% \mathrm{CI} 1.02,1.02)$, from the lowestincome quintile (OR 1.8, 95\% CI 1.7,1.8), and more rural (OR 1.6, 95\% CI 1.6,1.6) than controls. High-system users had a higher proportion of presentations by ambulance (OR 1.1 per 0.25 increase, 95\% CI 1.1,1.1) and disposition was admission/ transfer (OR 1.1 per 0.25 increase, 95\% CI 1.1,1.1), left without being seen (OR 1.1, 95\% CI 1.1,1.1), or left against medical advice (OR 1.1, 95\% CI 1.1,1.1) more often than controls.

Conclusion High-system users were more likely to be female, older, live in rural areas and within the lowest-income quintile compared to controls. Their heterogeneity in acuity, comorbid chronic diseases, and limited access to primary care suggests that interventions referring high-system users to primary care may be fruitful in reducing ED utilization by high-system users.
\end{abstract}

Keywords Emergency department $\cdot$ Frequent health service users

Electronic supplementary material The online version of this article (https://doi.org/10.1007/s43678-020-00013-7) contains supplementary material, which is available to authorized users.

Rhonda J. Rosychuk

rhonda.rosychuk@ualberta.ca

1 Department of Pediatrics, Faculty of Medicine and Dentistry, University of Alberta, 524 Edmonton Clinic Health Academy, Edmonton, AB T6G 1C9, Canada

2 Department of Obstetrics and Gynecology, University of Alberta, Edmonton, AB, Canada

3 School of Public Health, University of Alberta, Edmonton, AB, Canada

4 Department of Emergency Medicine, University of Calgary, Calgary, AB, Canada
5 Department of Community Health Sciences, University of Calgary, Calgary, AB, Canada

6 Emergency Strategic Clinical Network, Alberta Health Services, Edmonton, AB, Canada

7 Department of Emergency Medicine, University of Alberta, Edmonton, AB, Canada

8 Department of Statistics and Actuarial Science, Simon Fraser University, Burnaby, BC, Canada

9 Department of Mathematical and Statistical Sciences, University of Alberta, Edmonton, AB, Canada 


\section{Résumé}

Objectif Les utilisateurs fréquents des services d'urgence sont un groupe diversifié de patients qui représentent un nombre disproportionné de présentations aux services d'urgence. Cette étude a examiné les caractéristiques sociodémographiques et les visites aux urgences de grands utilisateurs adultes du système de santé dans deux provinces canadiennes.

Méthode Des cohortes de grands utilisateurs du système de santé ont été créées pour l'Alberta et l'Ontario, y compris les patients ayant fait l'objet des $10 \%$ de présentations les plus importantes dans le système national d'information sur les soins ambulatoires (avril 2015-mars 2016). Les contrôles étaient des échantillons aléatoires des patients ne faisant pas partie des grands utilisateurs. Les données sociodémographiques et les données sur les visites aux urgences ont été utilisées pour prédire l'appartenance à un groupe de grands utilisateurs du système dans un modèle de régression logistique multivariable. Résultats Il y avait 579674 de grands utilisateurs et 2115960 témoins. Les grands utilisateurs de système étaient plus susceptibles d'être des femmes (rapport des cotes $[R C]=1,1$, intervalle de confiance à $95 \%$ (IC) $1,1,1,1)$, plus âgés (RC $=$ $1,02$ tous les 5 ans, IC à $95 \% 1,02,1,02)$, d'après quintile de revenu le plus bas ( $\mathrm{RC}=1,8$, IC à $95 \% 1,7,1,8)$, et plus rural $(\mathrm{RC}=1,6, \mathrm{IC}$ à $95 \% 1,6,1,6)$ que les témoins. Les grands utilisateurs du système avaient une proportion plus élevée de présentations par ambulance ( $\mathrm{RC}=1,1$ pour une augmentation de 0,25 , IC à $95 \% 1,1,1,1)$ et la disposition était l'admission / transfert $(\mathrm{RC}=1,1$ pour une augmentation de 0,25 , IC à $95 \% 1,1,1,1)$, parti sans être vu $(\mathrm{OR}=1,1, \mathrm{IC}$ à $95 \% 1,1,1,1)$, ou parti contre l'avis médical (OR = 1,1, IC à $95 \% 1,1,1,1)$ plus souvent que les témoins.

Conclusions Les grands utilisateurs du système étaient plus susceptibles d'être des femmes, des personnes âgées, vivant dans des zones rurales et se situant dans le quintile de revenu le plus bas, par rapport aux témoins. Leur hétérogénéité en termes d'acuité, de comorbidité des maladies chroniques et d'accès limité aux soins primaires suggère que les interventions qui orientent les grands utilisateurs du haut système vers les soins primaires peuvent être fructueuses pour réduire l'utilisation des urgences par les grands utilisateurs du système

\section{Clinician's capsule}

\section{What is known about this topic?}

Frequent emergency department (ED) users have been estimated to account for between one third and one quarter of ED visits.

\section{What did this study ask?}

This study evaluated ED presentation characteristics associated with frequent ED use with a large Canadian dataset spanning many EDs.

\section{What did this study find?}

Frequent ED users were more likely female, older, rural, have lower income, chronically ill and have limited primary care access compared to controls.

\section{Why does this study matter to clinicians?}

Understanding frequent ED user characteristics can help improve primary care access, develop ED referral programs and potentially safely reduce acute care utilization.

\section{Introduction}

Emergency department (ED) presentations have increased in recent years along with the associated costs to health systems and prolonged waiting times for patients in urban, overcrowded EDs [1]. Frequent users of emergency departments (EDs) are a small number of patients who are responsible for a disproportionate number of ED presentations [2, 3]. It is estimated that $4.5-8 \%$ of all ED patients are frequent users and these patients account for 21-28\% of all ED presentations [2]. Recent systematic reviews [3, 4] have shown that frequent ED users were more likely to be younger, $[3,4]$ disproportionately sicker [3,] and more likely to have chronic illnesses [4] than non-frequent ED users. In the United States, frequent ED users were also more likely to have public insurance and be female than non-frequent ED users [3]. Another review identified misunderstandings of medical necessity and access issues (e.g., ease, timing, geography) as related to frequent ED use [5].

Prior studies of frequent users [6-10] have been conducted in a single jurisdiction and have not used population-based data. Understanding the characteristics of frequent users is important to develop effective strategies to provide optimal care to these individuals while mitigating effects of frequent visits on ED crowding [11-13]. This study described characteristics of patients and ED presentations associated with frequent ED use. The primary objective is to identify key factors that define adult frequent ED users. Patient and ED presentation characteristics are summarized and comparisons are made between high-system users and controls. 


\section{Methods}

\section{Study design and time period}

This cohort study used population-based administrative health databases from Alberta and Ontario, Canada from April 1, 2015 to March 31, 2016. The University of Alberta Health Research Ethics Board approved this study (Pro00078363). The funding organization had no input in the conduct and reporting of the study.

\section{Study setting}

The Dynamic Cohort of Complex, High System Users [14] based on acute care cost, highest length of stay, most frequent hospitalizations, and most frequent ED presentations was created as collaboration between the Canadian Institutes of Health Research and the Canadian Institute for Health Information. Alberta and Ontario are the only two provinces in Canada that report on all ED presentations to the National Ambulatory Care Reporting System [15]. In 2015-2016, Alberta had 2,336,794 ED presentations in the National Ambulatory Care Reporting System and Ontario had 6,279,031 ED presentations [16]. The Canadian Institute for Health Information extracted the data for these provinces and linked the data needed for this study. Data quality tests are done by the Canadian Institute for Health Information to flag suspect data quality issues and to support data providers in their own quality audits [17]. Examples of tests include flagging durations that are longer than reasonable thresholds and missing diagnosis codes.

\section{Population}

A cohort of high-system users was created by identifying the top $10 \%$ of adult (aged $\geq 18$ years) patients with respect to the number of ED presentations during the fiscal year for each province [14]. Control groups for each province were a random sample of adult patients not in the high-system user group during the fiscal year using a sampling ratio of $4: 1[14]$.

The National Ambulatory Care Reporting System database provides data on demographic characteristics of patients and characteristics of ED presentations including dates and times, triage level, diagnoses, and disposition status. Demographic data included age (in years) at ED presentation, sex, and the forward sortation area (first three characters of the postal code) of residence as a proxy for urban or rural location of residence. The full postal code was used to obtain distances from patients' home to hospital visited (kilometres $[\mathrm{km}]$ ). For Ontario, the demographic data included having a primary health care provider recorded (e.g., family physician, other, none). Mode of arrival included type of ambulance if an ambulance was used. Triage level is based on the Canadian Emergency Department Triage and Acuity Scale (CTAS) [18]. The triage codes are: resuscitation [1], emergency [2], urgent [3], semi-urgent [4], and non-urgent [5] and grouped for this study as CTAS $1 / 2$ vs. all others.

Diagnoses are provided as International Classification of Diseases (ICD-10-CA) [19] codes with up to 10 codes recorded. The main diagnosis code was classified into diagnosis categories using a combination of the Quan et al. adaptation [20] to the Deyo/Charlson comorbidity coding scheme (R package icd by Wasey, J O and R Core Team) and the classification of diagnoses from Guttmann et al. [21] Any overlapping ICD codes were kept only in the Quan et al. coding scheme to ensure mutually exclusive diagnosis categories. In addition, ambulatory care sensitive conditions were coded based on main diagnosis to examine important chronic conditions that may not have been classified by the two other coding classifications [22].

Patients were given one of 15 ED disposition codes and these were grouped as discharged (codes 1,15 ), admitted/ transferred $(6-9,12-14)$, death $(10,11)$, left without being seen $(2,3)$, and left against medical advice $(4,5)$. As patients had multiple visits, they are classified into categories for each variable if any of their visits related to this category. As an example, a patient may have 3 ED visits, 1 resulting in admission and 2 in left against medical advice. This patient would be part of the any admitted/transferred and any left against medical advice counts.

Data linkage with Statistics Canada 2011 census data provided neighborhood income quintiles and the population centre type (urban core, urban secondary core, centre, fringe, rural) based on population size and census area designations [23].

\section{Outcome measures}

The outcome was whether a patient was a member of the high-system user group.

\section{Data analysis}

The unit of analysis was the patient and characteristics were taken at the first ED presentation in the dataset for patientlevel variables (e.g., age). For data at the ED presentation level, binary variables were created to identify if any of the patient's ED presentations had that characteristic (e.g., any ED presentation with CTAS 1/2) and proportions of visits for a patient with this characteristic were determined. Numerical summaries (i.e., means, standard deviations [SDs], IQR represented as [25th, 75th percentiles], counts) described characteristics by province and group. Logistic regression models were developed to compare high-system 
user and control groups and provide odds ratios (ORs) and associated $95 \%$ confidence intervals (CIs). A full multivariable logistic regression model included all predictors as main effects. A separate interaction model allowed provincespecific estimates (see Supplementary Material). Predictor variables included demographic characteristics and patientspecific proportions of ED presentations that had a characteristic. A $p$ value $(p)$ less than 0.05 was considered to be statistically significant. Statistical analyses were conducted in R (R Project version 3.4.1).

\section{Results}

There were 579,674 high-system users and 2,115,960 controls in this study. In Alberta, 101,250 high-system users made 686,817 ED presentations (29.4\% of all ED presentations), for a median number of 5 (IQR 4, 7) ED presentations per person. There were 401,923 controls who made 560,755 ED presentations (median per person $=1$, IQR 1, 2). In Ontario, 478,424 high-system users made 2,222,173 ED presentations (35.4\% of all ED presentations) with a median of 4 presentations per person (IQR 3,5). There were 1,714,037 Ontario controls who made 2,113,961 ED presentations (median per person $=1, \mathrm{IQR} 1,1)$.

Table 1 provides demographic characteristics by highsystem user status. The high-system user group had more patients who were female and older, from lower-income quintiles, and living closer to a hospital than the control group. The Ontario patients were older than the Alberta patients, with 3.7 years difference in the average age of high-system users (Supplementary Table 1). The majority of patients were from large urban areas (with $20.9 \%$ of high-system users from rural areas compared to $16.4 \%$ of controls). Having a primary health care provider recorded was similar in both high-system user and control groups, although this variable was unknown for the vast majority of Alberta patients. The high-system user group had a higher proportion of patients living in areas with the lowest-income quintile (27.5\%) compared to the control group (21.2\%).

The ED presentation characteristics by high-system user status are provided in Supplementary Table 2. The high-system user group had proportionately more presentations that involved ambulances, occurred on weekends, and were CTAS 1 (resuscitation) or 2 (emergent). The high-system user group generally had more representation from each of the diagnosis categories (Supplementary Table 3) and from ambulatory care sensitive chronic conditions (Supplementary Table 4). Three to four times more high-system users than controls had at least one ED presentation for a diagnosis that could have a chronic component. The high-system users had more presentations that ended in admission than controls and more presentations that were left without being seen or left against medical advice.
The Alberta high-system user group had a higher proportion of these dispositions than the Ontario high-system user group (Supplementary Table 2).

Results of the full multivariable model (Supplementary Table 5) indicated that high-system users and controls differed on most demographic, ED presentation characteristics, and diagnosis categories. High-system users are more likely to be female, older, from rural population centers with lower income levels, and less likely to have a primary care provider. Larger odds ratios (i.e., OR > 1.5) were seen for some population centre types and lower-neighbourhood income quintiles. After adjusting for all other predictors, high-system users were more likely to be female (OR 1.1 95\% CI 1.1,1.1), older (OR 1.02 per 5 years $95 \%$ CI 1.02,1.02), live closer to hospital (OR 0.9 per $100 \mathrm{~km} \mathrm{95 \%} \mathrm{CI} \mathrm{0.9,0.9),} \mathrm{live} \mathrm{in} \mathrm{areas} \mathrm{other} \mathrm{than} \mathrm{large}$ urban centres (e.g., OR 1.6 for rural 95\% CI 1.6,1.6), and from areas in the lower-income quintiles than controls (OR 1.8 for the lowest-income quintile 95\% CI 1.7,1.8; Fig. 1).

The magnitude of the effects for sex and certain population types differed by province (Supplementary Table 6, Supplementary Fig. 1). In Ontario, high-system users were more likely to not have a primary health care physician than controls (OR 1.1, 95\% CI 1.1, 1.1). Primary care data were not available for Alberta. For ED presentation characteristics, high-system users had higher proportions of presentations arriving by ambulance, on weekdays, having less acuity (CTAS 3-5), and being admitted or transferred, left without being seen, or left against medical advice than controls (Fig. 2).

About $66 \%$ of high-system users had at least one visit where the main diagnoses were not captured by our coding scheme compared to $25 \%$ of controls (Supplementary Table 3). Compared to controls high-system users had higher proportions of presentations in the following main diagnosis categories: congestive heart failure, liver diseases, diabetes, renal disease, malignancy, and mental health. High-system users had lower proportions of presentations of myocardial infarction, peripheral vascular disease stroke, injury/ trauma, headache and other neurological conditions, chest pain, upper respiratory infections, skin problems, and general signs and symptoms (Fig. 3, Supplementary Table 5).

\section{Discussion}

\section{Interpretation of findings}

This large administrative data study used a cohort created in Alberta and Ontario for the top $10 \%$ of the most frequent ED users and a sample of controls from bottom $90 \%$ of users. The study described and compared sociodemographic and ED presentation characteristics between high-system users and controls. Overall, high-system users were more likely 
Table 1 Demographic characteristics by group for 2015/2016

Control $(2,115,960)$

$n(\%)$
High-

system User

$(579,674)$

$n(\%)$

\section{Province}

Alberta

Ontario

401,923 (19.0)

101,250 (17.5)

Ontario

Female

$1,714,037(81.0)$

$1,101,251(52.0)$

$1,014,686(48.0)$

Male

Age (years)

Mean (SD)

Travel distance to hospital $(\mathrm{km})$

48.6 (19.4)

$n=2,081,933$

$5.4(2.5,13.0)$

$n=2,110,482$

Second character of postal code

$344,714(16.3)$

$1,765,768$ (83.4)

Not 0 (proxy for urban)

Population type ${ }^{\mathrm{a}}$

$n=1,997,254$

Core

Secondary core

Population centre outside census metropolitan area/census agglomerations

Fringe

Rural area

Primary health care

Family physician

Unknown/unavailable (includes cases where patient is unconscious or arrives dead) (\%)

None

Other (ex. family health team, walk-in clinic)

Neighborhood income quintile

Lowest quintile

Medium-low quintile

Middle quintile

Medium-high quintile

Highest quintile
$1,453,256$ (72.8)

82,115 (4.1)

$76,582(3.8)$

$58,390(2.9)$

326,911 (16.4)

$n=2,115,839$

$1,499,234$ (70.9)

468,652 (22.1)

135,645 (6.4)

$12,308(0.6)$

$n=2,091,010$

444,121 (21.2)

435,256 (20.8)

434,235 (20.8)

403,009 (19.3)

374,389 (17.9)
478,424 (82.5)

321,155 (55.4)

258,513 (44.6)

51.1 (21.5)

$n=569,320$

$4.6(1.8,12.8)$

$n=576,244$

133,948 (23.1)

442,296 (76.3)

$n=528,404$

$344,042(65.1)$

20,033 (3.8)

$38,454(7.3)$

$15,661(3.0)$

110,214 (20.9)

$n=579,605$

$418,829(72.3)$

$116,700(20.1)$

39,024 (6.7)

$5052(0.9)$

$n=571,373$

156,965 (27.5)

$127,372(22.3)$

113,141 (19.8)

96,733 (16.9)

77,162 (13.5)

$n$ count, $Q 1$ 25th percentile, $Q 3$ 75th percentile, $S D$ standard deviation

${ }^{a}$ Population centre type depends on population size and census metropolitan area (CMA) and census agglomeration (CA) designation [22]. Urban areas have $\geq 1000$ people with a population density of $\geq 400$ persons per $\mathrm{km}^{2}$ and include the core (large urban area with $\geq 50,000$ people for a CMA or $\geq 10,000$ for a CA), secondary core (core merged with an adjacent CMA or larger CA), population centres outside CMA/CAs, and fringe (all small urban areas within a CMA or CA that are not contiguous with the core of the CMA or CA) classifications [22]. A rural area is a region within a CMA or CA that is not core or fringe [22]

Fig. 1 Forest plot of odds ratios and $95 \%$ confidence intervals for high-system users vs. controls of demographic characteristics from the full multivariable model for 2015/2016 (estimates in Supplementary Table 4)

\author{
Alberta \\ Female \\ Age (per 5y) \\ Travel distance (per 100km) \\ Type: Secondary core \\ Type: Population centre \\ Type: Fringe \\ Type: Rural area \\ Income: Lowest \\ Primary health care: None (Ontario)
}

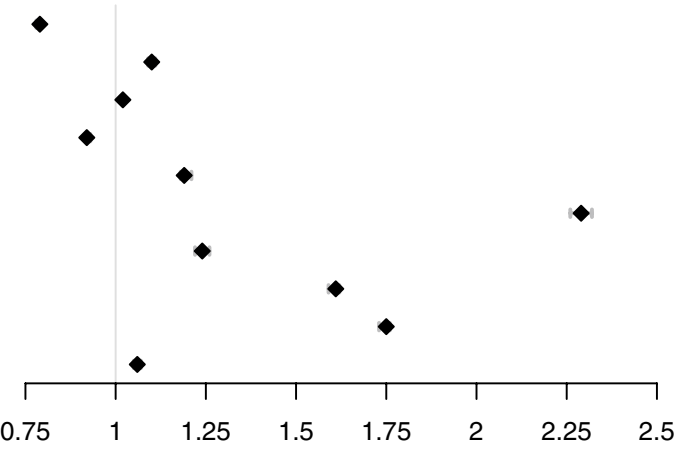




\section{Ambulance \\ Weekend \\ Night shift (00:00-07:59) \\ Triage levels $1 / 2$ \\ Admissions/transfers \\ Left without being seen \\ Left against medical advice}

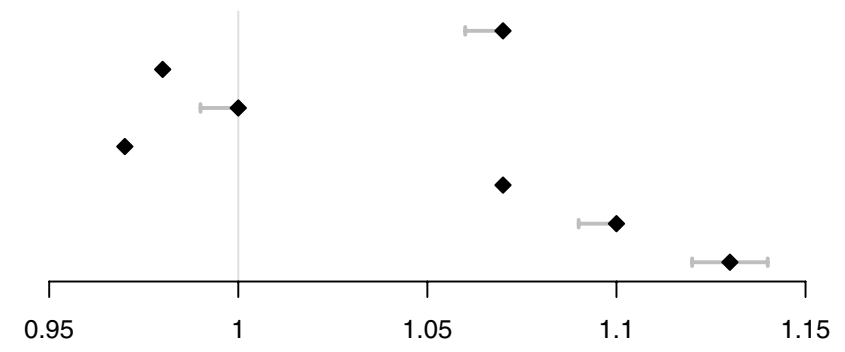

Fig. 2 Forest plot of odds ratios and 95\% confidence intervals for high-system users vs. controls based on an 0.25 increase in proportion for emergency department presentation characteristics from the full multivariable model for 2015/2016 (estimates in Supplementary Table 4)

Fig. 3 Forest plot of odds ratios and $95 \%$ confidence intervals for high-system users vs. controls based on an 0.25 increase in proportion for main diagnosis category from the full multivariable model for 2015/2016 (estimates in Supplementary Table 4)

\author{
AIDS/HIV \\ Cancer \\ Chest pain \\ Chronic pulmonary disease \\ Congestive heart failure \\ Dementia \\ Diabetes \\ Fever \\ Gastrointestinal \\ General signs and symptoms \\ Genitourinary/obstetric \\ Headache and other neurological \\ Hemiplegia or paraplegia \\ Injury/trauma \\ Liver mild \\ Liver severe \\ Mental health \\ Metastatic solid tumor \\ Myocardial infarction \\ Peptic ulcer disease \\ Peripheral vascular disease \\ Renal disease \\ Rheumatic disease \\ Shortness of breath \\ Skin problems \\ Stroke \\ Upper respiratory tract infections
}

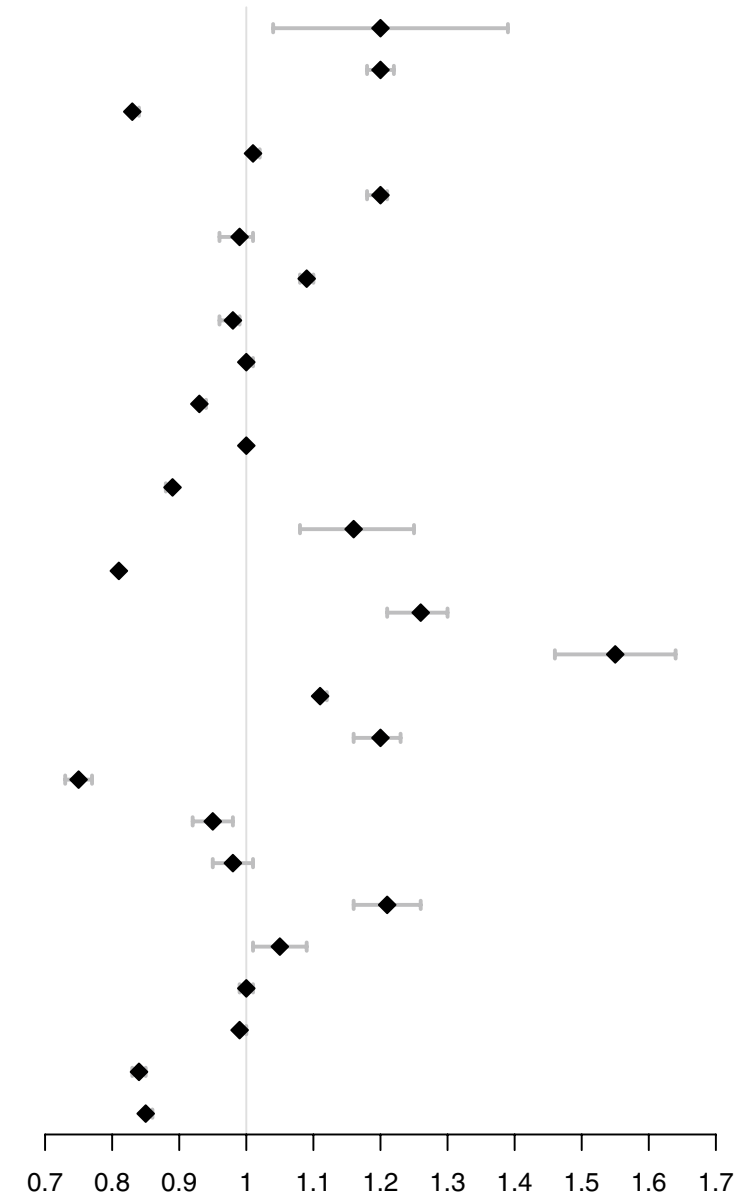

to be female, older, from the lowest-income quintile, and living in rural areas compared to controls. The odds ratios were similar in each province except for female and rural, where Alberta had higher odds ratios compared to Ontario. High-system users were more likely to have no primary health care provider than controls, had a higher proportion of presentations where arrival was by ambulance and disposition was admission/transfer, left without being seen, or left against medical advice than controls. High-system users had a higher frequency of visits for chronic medical and mental health conditions.

\section{Comparison to previous studies}

This study identified a high heterogeneity in the sociodemographic characteristics of high-system users and brought unique insights into the acuity and patterns of their ED presentations. Some of our findings agree with results from other jurisdictions [24]. Some studies have also associated highsystem users with being female [3], being older [7], being from lower incomes $[3,4,7]$, higher use of ambulances [3, 4], and lower severity [4]. High-system users in our study were more likely to be rural in agreement with some studies 
[7] but our study and other studies have indicated that highsystem users have closer proximity to EDs [3, 5]. Our results in Ontario suggested that high-system users were less likely to have a listed primary health care physician. This finding is contrary to a New Brunswick study that found frequent ED attenders were more likely to have listed primary care providers [10], but consistent with a Manitoba study in which frequent ED users were more likely to see a number of different primary care physicians [7].

Our findings that high-system users were more likely to be admitted/transferred, leave without being seen, or leave against medical advice than controls highlight the heterogeneity of the high-system user group. Some may be presenting to the ED for relatively minor conditions because they have less access to other health care options, while others may have serious conditions that require inpatient care. Some may present to the ED because it is easier to access [5]. Both lower [9] and higher [25] risks of admission have been reported for high-system users in other studies [4, 24]. Increased left without being seen and left against medical advice have also been reported in patients with $\geq 20 \mathrm{ED}$ presentations in a year compared to patients presenting once [26]. In agreement with similar studies, high-system users had higher proportions of presentations for many chronic and mental health conditions $[3,4,7,8]$.

\section{Strengths and limitations}

Our study used large, population-based databases with standardized data reported for two Canadian provinces. Our results may not be generalizable to other areas of Canada or jurisdictions with different health care systems. Our analyses are limited to data fields collected by the National Ambulatory Care Reporting System and some of these fields had missing data. About $6 \%$ of patients had missing values for variables in the regression modeling. Patients with chronic conditions are an important population to consider in the context of frequent users of EDs. However, the diagnosis codes in the ED do not necessarily identify patients with chronic diseases, and it is difficult to classify an ED presentation as related to a chronic or acute condition. Casefinding algorithms developed to identify chronic conditions are often based on inpatient admissions and physician claims in outpatient settings; therefore, the National Ambulatory Care Reporting System does not provide all the information needed to identify patients with chronic conditions. Many diagnosis codes commonly seen in high-system users have been previously documented as being ambulatory-sensitive conditions, meaning that they are ameliorated by longitudinal primary care. Finally, we did not have access to other health services use data (e.g., physician claims), so we cannot determine if high-system users of ED services are also high users of other health services.

\section{Clinical implications}

Our findings suggest that high-system users are a heterogeneous group, who may have varying reasons for frequent ED use. Several strategies tailored to unique demographics (e.g. seniors, low income, those with chronic or complex illness, such as cancer, those with mental health complaints) may be required to meet the healthcare needs of these patients and potentially to safely reduce the resource burden of highsystem users. The preponderance of rural high-system users, and those with no linked primary care provider, suggests that efforts to improve primary care access in some areas or for EDs to link patients to existing resources may improve both ED utilization and patient outcomes. Better access to longitudinal specialist care for chronic conditions or mental illness may also reduce the need for ED use among highsystem users. Similarly, access to complex care or adequate management of chronic conditions may improve patient care and ED utilization. [26].

\section{Research implications}

More granular quantification of characteristics of high-system users within provinces-or in smaller jurisdictions, such as health region, may identify differential causes of highsystem users that can be addressed with targeted interventions. Comparisons of high ED use for specific chronic and mental health conditions or demographic groups may also suggest strategies for intervention. Some studies have shown that case management reduces ED presentations and costs [27]. These data could be used in future studies to develop predictive models to identify patients who may become high-system users in the future, and provide alternative care options that safely reduce ED utilization.

\section{Conclusion}

High-system users are a heterogeneous group of patients in the ED. They are more likely to be female, older, from lowincome areas, rural, and have limited primary care access. A greater proportion of their ED presentations had lower acuity and ended in admission/transfer, left without being seen, and left against medical advice than controls. Strategies tailored to diverse high-system user demographics, based on our findings and further analysis, may improve healthcare for high-system users while potentially safely reducing acute care utilization.

Acknowledgements The authors thank Prof. Howard Ovens MD from the University of Toronto for helping to secure grant funding and for insightful comments. The authors thank the Canadian Institute for Health Information for providing health datasets. Parts of this material 
are based on data and information provided by the Canadian Institute for Health Information. However, the analyses, conclusions, opinions and statements expressed herein are those of the author and not those of the Canadian Institute for Health Information.

Funding This study was supported by a grant from the Canadian Institutes of Health Research (\#394223). The funding source had no direct involvement in the study design, analysis, interpretation or decision to submit this work.

\section{Compliance with ethical standards}

Conflict of interest The author declares that there is no competing interest.

\section{References}

1. Affleck A, Parks P, Drummond A, Rowe B, Ovens H. Emergency department overcrowding and access block. CJEM. 2013;15(6):59-67.

2. LaCalle E, Rabin E. Frequent users of emergency departments: the myths, the data, and the policy implications. Ann Emerg Med. 2010;56(1):42-8.

3. Giannouchos TV, Kum H-C, Foster MJ, Ohsfeldt RL. Characteristics and predictors of adult frequent emergency department users in the United States: a systematic literature review. J Eval Clin Pract. 2019;25(3):420-33.

4. van Tiel S, Rood PPM, Bertoli-Avella AM, Erasmus V, Haagsma J, van Beeck E, et al. Systematic review of frequent users of emergency departments in non-US hospitals: state of the art. Eur J Emerg Med. 2015;22(5):306-15.

5. Burns TR. Contributing factors of frequent use of the emergency department: a synthesis. Int Emerg Nurs. 2017;35:51-5.

6. Chan BTB, Ovens HJ. Frequent users of emergency departments. Do they also use family physicians' services? Can Fam Physician. 2002;48:1654-60.

7. Doupe MB, Palatnick W, Day S, Chateau D, Soodeen R-A, Burchill C, et al. Frequent users of emergency departments: developing standard definitions and defining prominent risk factors. Ann Emerg Med. 2012;60(1):24-32.

8. Gaulin M, Simard M, Candas B, Lesage A, Sirois C. Combined impacts of multimorbidity and mental disorders on frequent emergency department visits: a retrospective cohort study in Quebec, Canada. CMAJ. 2019;191(26):E724-32.

9. Geurts J, Palatnick W, Strome T, Sutherland KA, Weldon E. Frequent users of an inner-city emergency department. CJEM. 2012;14(5):303-13.

10. Palmer E, Leblanc-Duchin D, Murray J, Atkinson P. Emergency department use: is frequent use associated with a lack of primary care provider? Can Fam Physician. 2014;60:e223-9.

11. Rowe BH, Bond K, Ospina MB, Blitz S, Friesen C, Schull M, et al. Emergency department overcrowding in Canada: what are the issues and what can be done? [Technology overview no 21]. Ottawa: Canadian Agency for Drugs and Technologies in Health; 2006.

12. Rowe BH, McRae A, Rosychuk RJ. Temporal trends in emergency department volumes and crowding metrics in a western Canadian province: a population-based, administrative data study. BMC Health Serv Res. 2020;20:356.

13. Morley C, Unwin M, Peterson GM, Stankovich J, Kinsman L. Emergency department crowding: a systematic review of causes, consequences and solutions. PLoS One. 2018;13(8):e0203316.

14. Canadian Institutes of Health Research, Canadian Institute for Health Information. Dynamic Cohort of Complex, High System Users-2011-2015: A CIHR-CIHI Collaboration. Ottawa, ON: Canadian Institutes of Health Research and Canadian Institute for Health Information; 2017.

15. Canadian Institute for Health Information. National Ambulatory Care Reporting System (NACRS). Ottawa, ON: Canadian Institute for Health Information.

16. Canadian Institute for Health Information. Data Quality Documentation, National Ambulatory Care Reporting System-Current-Year Information, 2015-2016. https://www.cihi.ca/sites/defau 1t/files/document/nacrs-dataquality_2015-2016_en.pdf. Ottawa, ON: Canadian Institute for Health Information; 2016.

17. Canadian Institute for Health Information. National Ambulatory Care Reporting System Open-Year Data Quality Test Specifications, 2017-2018. https://www.cihi.ca/sites/default/files/docum ent/nacrs-2017-2018-oydq-specs.pdf. Ottawa, ON: Canadian Institute for Health Information; 2017.

18. Bullard MJ, Unger B, Spence J, Grafstein E, CTAS National Working Group. Revisions to the Canadian Emergency Department Triage and Acuity Scale (CTAS) adult guidelines. CJEM. 2008;10(2):136-51.

19. Canadian Institute for Health Information. The Canadian Enhancement of ICD-10 (International Statistical Classification of Diseases and Related Health Problems, Tenth Revision). Ottawa: Canadian Institute for Health Information; 2001.

20. Quan H, Sundararajan V, Halfon P, Fong A, Burnand B, Luthi J-C, et al. Coding algorithms for defining comorbidities in ICD-9-CM and ICD-10 administrative data. Med Care. 2005;43(11):1130-9.

21. Guttmann A, Schull MJ, Vermeulen MJ, Stukel TA. Association between waiting times and short term mortality and hospital admission after departure from emergency department: population based cohort study from Ontario. Canada. BMJ. 2011;342:d2983.

22. Sanmartin C, Khan S, LHAD Research Team. Hospitalizations for Ambulatory Care Sensitive Conditions (ACSC): the factors that matter. Ottawa: Statistics Canada; 2011.

23. Statistics Canada. Postal Codes Conversion File (PCCF), Reference Guide, May 2011 Postal Codes. Statistics Canada Catalogue no. 92-153-G. Ottawa; 2011.

24. Moe J, Kirkland S, Ospina MB, Campbell S, Long R, Davidson A, et al. Mortality, admission rates and outpatient use among frequent users of emergency departments: a systematic review. Emerg Med J. 2016;33(3):230-6.

25. Oliveira A. Hyperusers and emergency. Acta Med Port. 2009;21(6):6.

26. Ruger JP, Richter CJ, Spitznagel EL, Lewis LM. Analysis of costs, length of stay, and utilization of emergency department services by frequent users: implications for health policy. Acad Emerg Med. 2004;11(12):1311-7.

27. Althaus F, Paroz S, Hugli O, Ghali WA, Daeppen J-B, Peytremann-Bridevaux I, et al. Effectiveness of interventions targeting frequent users of emergency departments: a systematic review. Ann Emerg Med. 2011;58(1):41-52. 